\title{
FORMAS DE ORGANIZAÇÃO E ENREDAMENTO PARA AÇÕES SOCIOPOLÍTICAS
}

\section{Sonia Aguiar}

\section{Resumo}

Formas organizativas baseadas em dinâmicas de enredamento entre ONGs e movimentos sociais têm surgido e se fortalecido no Brasil, sobretudo nos últimos 15 anos, sob diferentes denominações: aliança, articulação, coalizão, fórum, rede. São configurações que se diferenciam das redes sociais de indivíduos porque seus nós são "representações" coletivas de interesses, necessidades e identidades de grupos, comunidades e populações. Suas ações coletivas envolvem processos participativos e colaborativos fortemente apoiados em produção, apropriação e compartilhamento de conhecimento e saberes especializados, que orientam escolhas ideológicas, estratégias discursivas de contra-argumentação e táticas de intervenção nas arenas e agendas da esfera pública. Para isso, precisam contar em seus quadros, ou entre os seus colaboradores, com profissionais capacitados tanto na academia quanto na aprendizagem coletiva das lutas sociais - das locais às globais.

\section{INTRODUÇÃO}

A Análise de Redes Sociais (ARS) desenvolveu-se desde os anos 1940 no âmbito da Antropologia, da Sociologia e da Psicologia Social preocupada com as interações promovidas por indivíduos e grupos sociais em suas relações cotidianas de interesses, afinidades e satisfação de necessidades. A partir da década de 1980, porém, os estudos nessa área começam a refletir as novas demandas das sociedades complexas e despertam o interesse de ou-

\section{Palavras-Chave}

redes sociais; ONGs e movimentos sociais; saberes especializados; contra-argumentação; racionalidade estratégica

tras disciplinas, entre as quais a Economia, a Geografia, a Ciência Política e a Ciência da Informação.

Nessa trajetória, os chamados novos movimentos sociais aparecem como objeto de conhecimento de interesse crescente. No entanto, o ferramental teóricometodológico da ARS - marcadamente estruturalista, funcionalista e egocentrado não tem dado conta de captar a dinâmica desses movimentos, cada vez mais articulados em redes cujos nós, na maioria das 
vezes, não são indivíduos, mas "representações" de um coletivo ${ }^{1}$. A literatura internacional sobre abordagens relacionais de movimentos sociais também não oferece muitas contribuições relevantes à analise das redes brasileiras que promovem ações coletivas, em função dos determinantes sóciohistóricos que geraram padrões discrepantes de cidadania e, em conseqüência, diferenças significativas quanto ao papel das organizações sem fins lucrativos e não-governamentais (genericamente chamadas, no Brasil, de ONGs).

A atenção dos pesquisadores europeus e estadunidenses tem se mantido fortemente centrada em movimentos reivindicativos e associativos ligados aos direitos civis (típicos de contextos em que os direitos humanos e de cidadania básicos já estão, em princípio, garantidos), que promovem protestos, insurgências, revoltas e outros tipos de manifestações "dramatúrgicas" (de uma passeata silenciosa de nudistas em pleno inverno a quebra-quebras incendiários, por exemplo). Sistematização recente feita por Diani e McAdam (2003), com base em extensa bibliografia (incluindo títulos de autores brasileiros), evidencia essas distâncias empíricas e teóricoconceituais, embora também ofereça al-

\footnotetext{
${ }^{1}$ Das 196 entidades que responderam ao questionário da pesquisa sobre o perfil das associadas da Abong (de um total de 248 organizações), em 2002, apenas 17 deixaram em branco a questão referente a "conselhos, redes e fóruns de que participa", segundo Soczek (2007, p.120).
}

gumas abordagens interessantes para estudo das novas articulações entre ONGs e movimentos sociais observáveis na realidade brasileira contemporânea.

Este artigo faz uma primeira aproximação analítica de formas organizativas de ações coletivas de caráter sociopolítico, a partir de um campo empírico bem delimitado: as entidades vinculadas à Inter-redes Direitos e Política, que se apresenta como um "espaço de articulação de redes e fóruns de organizações da sociedade civil brasileira que atuam de diversas formas e em diversos temas, para o fortalecimento da esfera pública, promoção de direitos e proposição de políticas". ${ }^{2}$ Esta articulação começou a ser delineada em 2002, a partir de uma "convocação" da Associação Brasileira de Organizações Não Governamentais (Abong), que mobilizou 16 redes e fóruns de ONGs e movimentos sociais com o objetivo de "pensarem sua ação" no processo eleitoral daquele $a^{3}{ }^{3}$. Este grupo elaborou uma Carta aos Candidatos e se reuniu com o então candidato Lula, a convite dele, "para debater sobre a relação das ONGs com seu eventual governo".

O encontro estreitou o mútuo conhecimento entre as redes e fóruns e inscreveu na agenda comum a disposição de constituição de um espaço de articulação. O grupo iniciava, ali, um processo de discus-

\footnotetext{
Apresentação institucional no site $<$ http://www.inter-redes.org.br/>

3 A quarta disputa de Luiz Inácio Lula da Silva à Presidência da República, na qual acabou finalmente eleito.
} 
são sobre pautas comuns, formas de relação com o novo governo, propostas para concretizar mais amplamente os princípios e as conquistas que têm alimentado as lutas sociais, entre outros aspectos. Neste sentido, foram sendo organizados encontros para analisar a conjuntura e trocar experiência organizativa, que resultaram na formação de um espaço permanente, aberto e construído em processo, a Inter-Redes.

Essa racionalidade estratégica que orientou a formação da Inter-Redes leva a um olhar sobre as ONGs e movimentos sociais não do ponto de vista da "questão social", como é predominante, mas da "cultura política pública”, isto é, considerando e problematizando as ações coletivas de enfrentamento das instâncias de poder na disputa pela mobilização dos recursos públicos em favor das populações pobres, de comunidades marginalizadas, de grupos desfavorecidos ou socialmente discriminados.

Concebemos a cultura política como um conjunto de valores, crenças, atitudes, comportamentos sobre a política, entendida como algo além daquela que se desenrola nos parlamentos, no governo, ou no ato de votar. Política com "P" maiúsculo, relativa à arte da argumentação e do debate dos temas e problemas públicos (...). O conjunto de percepções e de visões de mundo que um grupo constrói no processo de experiência histórica ao atuarem coletivamente, aliado às representações simbólicas que também constroem ou adotam, são a parte mais relevante da cultura política de um grupo porque é a partir destes elementos que o grupo constrói a sua identidade. [...] A cultura política pública pressupõe uma cultura ética, com civilidade e respeito ao outro. Essa nova cultura política se contrapõe à tradição autoritária que desconhece a existência de esferas públicas, assim como se contrapõe também às práticas clientelistas ou corporativas de grupos patrimonialistas, oligárquicos, ou modernos/ privatistas. Trata-se de uma cultura política gerada por processos nos quais diferentes interesses são reconhecidos, representados e negociados, via mediações sociopolíticas e culturais (GOHN, 2005, p.34-35, grifo da autora).

Essa visão sociopolítica e cultural do "interesse público" gera uma demanda crescente de conhecimentos especializados e de articulação de informações atualizadas entre os participantes das redes sociais que privilegiam a interpelação das práticas políticas, fundamentais tanto para o enfrentamento das instâncias de poder quanto para a proposição de alternativas contra-hegemônicas e viabilização de processos emancipatórios. Trata-se de um novo tipo de protagonismo que emerge na sociedade civil brasileira e se expressa, sobretudo, nas redes temáticas de abrangência local, regional, nacional e transnacional. "Quando surge um fato mais abrangente, as redes temáticas se entrecruzam" (GOHN, 2002, p.90). 
2 CONFIGURAÇÕES DA SOCIEDADE CIVIL ORGANIZADA NO BRASIL

Não há entre as ONGs (mesmo as consideradas "cidadãs"), os movimentos sociais e as redes que os aglutinam, no Brasil, uma visão consensual sobre o significado e o papel do que chamam genericamente de "sociedade civil". Segundo Gohn (2005, p.70), o termo foi introduzido no vocabulário político corrente da década de 1970, ainda no processo de resistência à ditadura militar, e desde então tornou-se objeto de elaboração teórica, no contexto das formações sociais do Brasil e da América Latina.

É possível identificar entre muitos ativistas dessas redes um alinhamento com a concepção gramsciana, que "destaca a importância da organização da sociedade civil para a mudança da sociedade política", através de "táticas e estratégias denominadas guerra de posição e de movimento", que visam democratizar os apareIhos do Estado (GOHN, 2005, p.65). Mas nota-se, também, idéias alinhadas à tipificação ideal da sociedade civil derivada dos

\footnotetext{
${ }^{4}$ Termo utilizado por Maria da Gloria Gohn (2005, p.14) para qualificar as organizações nãogovernamentais "que demandam e constroem ações pela cidadania (em lutas contra a pobreza, a exclusão e a discriminação)". Esta particularização se faz necessária no contexto deste artigo porque, como lembra Sergio Haddad (citado por GOHN, 2005, p.94): "Uma das dificuldades em compreender a natureza e o papel das ONGs está no fato de que, sob uma mesma nomenclatura, podemos encontrar uma infinidade de entidades, com histórias, tamanhos, missões, modelos organizacionais e mecanismos de sustentabilidade completamente diferentes uns dos outros".
}

acontecimentos históricos das últimas décadas do século XX, observada por Jeffrey C. Alexander (1998), citado por Gohn (2005, p.66-68). Nesta concepção, a sociedade civil é algo maior do que um guardachuva que abrigaria tudo o que não está no âmbito estatal, como se pensava no início da modernidade, antes de a "mão invisível do mercado" aprisionar corações e mentes. Ela passa a ser vista como um espaço que vai além das ações individuais, onde se deve construir um senso coletivo de obrigações e responsabilidades sociais; "uma esfera solidária na qual um certo tipo de comunidade universal cresce gradualmente, expressa pela opinião pública" (idem).

O processo de recuperação do "Estado de Direito" e de redemocratização da vida civil pública nacional, a partir de meados dos anos 1980, incorporou ao discurso sobre a sociedade civil um outro conceito, o de cidadania, sobretudo com a vivência histórica da campanha "Diretas Já", em 1984; a mobilização pró-emendas populares à Carta Constituinte, entre 1986-88; os movimentos pela Ética na Política e pelo impeachment do presidente Collor, em 1992; e o inédito voluntariado da Ação da Cidadania contra a Fome, a Miséria e pela Vida, entre 1993-97. A noção de cidadania que emerge dessas experiências de participação é devidamente atualizada e adaptada à realidade brasileira, marcada por profundas e duradouras desigualdades 
socioeconômicas, socioculturais e socioes-

paciais: modernos centros urbanos versus periferias desordenadas e desprovidas de serviços básicos; urbano como sinônimo de moderno versus rural como representação do "arcaico"; metrópoles do CentroSul-Sudeste versus "rincões" do NorteNordeste.

A cidadania nos anos 90 foi incorporada nos discursos oficiais e ressignificada na direção próxima à idéia de participação civil, de exercício da civilidade, de responsabilidade social dos cidadãos como um todo, porque ela trata não apenas dos direitos mas também dos deveres, ela homogeneiza os atores. Estes deveres envolvem a tentativa de responsabilização dos cidadãos em arenas públicas, via parcerias nas políticas sociais governamentais.

[...]

No novo cenário, a sociedade civil se amplia para se entrelaçar com a sociedade política, colaborando para o caráter contraditório e fragmentado que o Estado passa a ter nos anos 90. Desenvolve-se o novo espaço público denominado público não-estatal, onde irão situar-se conselhos, fóruns, redes e articulações entre a sociedade civil e representantes do poder público para a gestão de parcelas da coisa pública que dizem respeito ao atendimento das demandas sociais (GOHN, 2005, p.75 e 77).

É nesse contexto que surgem ou se fortalecem novos atores sociais, como as ONGs-cidadãs (que se diferenciam das organizações filantrópicas, assistencialistas e prestadoras de serviços sociais a "populações carentes") e as entidades do cha- mado "terceiro setor" (geralmente ligadas a fundações privadas vinculadas ou financeiramente apoiadas por empresas), que tanto se aliam quanto competem com os movimentos populares na organização de ações coletivas e na interlocução com o poder público para atendimento das demandas sociais. Obviamente, os rearranjos entre antigos e novos atores não ocorrem sem tensões entre as lideranças de cada campo na condução dos processos sociopolíticos, "principalmente em questões como: institucionalização, participação ou não em conselhos propostos ou criados pelo poder público, participação em programas governamentais etc" (GOHN, 2005, p.80), além do falso dilema entre assistencialismo e mudanças estruturais, que veio à tona na primeira fase da Ação da Cidadania.

Paralelamente, de forma quase invisível, uma "elite" das ONGs que trabalhavam com a temática do desenvolvimento social passa a se articular com organizações congêneres no cenário internacional e se torna protagonista de uma nova pauta política de abrangência global: a do desen-

\footnotetext{
${ }^{5}$ Expressão utilizada desde o início da década de 1990 para enquadrar "qualquer forma de atuação de organizações privadas sem fins lucrativos dirigida a finalidades públicas", como sintetizou Lisboa (2003). Para Montaño (2002), "terceiro setor" é uma denominação ideológica que marca a contrapartida do mercado e de parte da sociedade à retirada paulatina da responsabilidade estatal no trato da "questão social", no contexto da reforma neoliberal do Estado e do processo de reestruturação do capital em âmbito global. O uso do termo entre aspas é uma opção conceitual do autor, compartilhada por este artigo, que só se refere a Terceiro Setor em citações diretas de outros autores.
} 
volvimento sustentável. Ou seja, traz de fora o método de se articular em redes sociais via redes eletrônicas para compartiIhar conhecimento e experiências e, assim, aumentar a amplitude da sua capacidade de mobilização, interlocução e influência sobre as instâncias de poder, embora neste momento de forma ainda muito incipiente. Esse processo - que se tornaria irreversível na virada do século $X X$ - tem início em 1990, durante a preparação do Fórum Global, evento paralelo e alternativo à Conferência da ONU sobre Meio Ambiente e Desenvolvimento (ECO-92 ou Rio-92).

$\mathrm{Na}$ segunda metade da década de 1990, "o desmonte de políticas sociais pelas políticas neoliberais e sua substituição por outras políticas, em parceria com ONGs e outras entidades do Terceiro Setor" (GOHN, 2005, p.81) leva a novas rearticulações no campo das lutas sociopolíticas. As mudanças nos critérios de distribuição e gestão dos fundos públicos e sua aplicação em projetos de parceria com organizações sociais não só acirram a competição entre ONGs, movimentos sociais e "terceiro setor", como influem na pauta das reivindicações, já que os recursos passam a ser redirecionados das questões sociais "universais" (educação, saúde, moradia, etc) para clientelas focalizadas (crianças, jovens, mulheres, etc).

A palavra de ordem desses projetos e programas é ser propositivo e não apenas reivindicativo, ser ativo e não apenas um passivo reivindicante. Muitos movimentos se transformaram em ONGs ou se incorporaram às ONGs que já os apoiavam. A atuação por projetos exige resultados e tem prazos. Criou-se uma nova gramática na qual a idéia de mobilizar deixou de ser para o desenvolvimento de uma consciência crítica ou para protestar nas ruas. Mobilizar passou a ser sinônimo de arregimentar e organizar a população para participar de programas e projetos sociais, a maioria dos quais já vinha totalmente pronta e atendia a pequenas parcelas da população. O militante foi se transformando no ativista organizador das clientelas usuárias dos serviços sociais (GOHN, 2005, p.83).

A partir de então as ONGs-cidadãs, que têm perfil ideológico definido, vão ampliando o seu processo de enredamento visando, de um lado, afirmar sua identidade diferencial do "terceiro setor" e, de outro, enfrentar a crise de financiamento através do compartilhamento de recursos e de conhecimento em projetos políticos comuns.

A força política de um movimento
ou grupo é dada pelo projeto políti-
co que ele constrói, pelos valores
que o sustentam, pelo impacto que
suas ações provocam na sociedade
civil e política, pelos desafios que
enfrenta e a forma como faz isso;
pelos resultados qualitativos que
obtém com suas ações e pelos re-
sultados quantitativos (dado pelo
número de conquistas e derrotas
que se obtém na trajetória de a-
ções, considerando um período mí-
nimo do ciclo de existência do cole-
tivo organizado) (GOHN, 2005,
p.38). Segundo Gohn (2005, p.89), a maioria das ONGs-cidadãs que sobreviveram à 
crise de financiamento passou a adotar a perspectiva de intervenção direta no meio popular, e não apenas de assessoria, como ocorria desde os anos 1980, conferindo-Ihes um novo protagonismo, que tem como perspectiva produzir conhecimentos e democratizar informações.

\section{TRAJETÓRIA DAS REDES SOCIOPO- LÍTICAS}

Das 43 entidades que hoje fazem parte da Inter-redes ${ }^{6}$, foram selecionadas 22 para este estudo ${ }^{7}$, com base nos seguintes critérios: a) utilizarem a Internet como uma extensão da esfera pública na qual atuam, não só com o objetivo de dar visibilidade a suas ações mas também como espaço complementar de mobilização, interação e empoderamento, através da disseminação e do intercâmbio de informações táticas e de conhecimento estratégico ${ }^{8}$; b) apresentarem-se publicamente como rede, articulação, coalizão, aliança ou fórum de ONGs, movimentos sociais e outras entidades relacionadas a defesa de interesses da soci-

\footnotetext{
6 Com base na listagem disponível em <http:// www.inter-redes.org.br/> (Institucional/ Redes e fóruns), em 2 ago 2007.

${ }^{7}$ Ver listagem no final deste artigo.

${ }^{8}$ Duas importantes redes de atuação nacional desde os anos 1990 foram deixadas de fora por problemas de inacessibilidade de seus sites: a Rede Feminista de Saúde <http://www.redesaude.org.br> e a Rebea - Rede Brasileira de Educação Ambiental <http://www.rebea.org.br>, cujas páginas hospedadas por sua secretaria-executiva (http://www.ecomarapendi.org.br/Rebea/MalhaRede s/listaredes.htm) não continham informações institucionais.
}

edade como um todo, de grupos sociais identitários (mulheres, negros, homossexuais, etc), de comunidades ou de segmentos populacionais específicos (índios, quilombolas, atingidos por barragens etc); c) explicitarem, nessa apresentação, objetivos de intervenção, participação, contribuição, formulação e/ou monitoramento de políticas públicas e/ou de garantia de direitos humanos e de cidadania; d) indicarem as formas descentralizadas de mobilização e interação através das quais desenvolvem suas ações coletivas. ${ }^{9}$

Entende-se, aqui, por "redes sociopolíticas" as formas de organização e articulação descentralizadas entre atores sociais que tenham entre os seus objetivos, explicitamente, intervir nas arenas e agendas de políticas públicas, nos mais variados temas e em quaisquer das suas esferas local, estadual, nacional, regional ou global (nestes dois últimos casos referindo-se aos espaços institucionais intergovernamentais e multilaterais). Nesse sentido, a noção de

\footnotetext{
9 Entre as entidades vinculadas à Inter-redes encontram-se algumas que, apesar de se identificarem como "rede" e de participarem de articulações sistemáticas com outras organizações, não podem ser enquadradas como tal por serem organizações privadas, ainda que sem finalidade lucrativa; ou por constituir-se como personalidade jurídica de caráter representativo, como a Abong (cujo slogan no site <http://www.abong.org.br> é "Uma rede a serviço de um mundo mais justo, solidário e sustentável"). São o que se pode chamar de ONGs-rede, como a Redeh - Rede de Desenvolvimento Humano $<$ http://www.redeh.org.br>, fundada em 1990, e a RITS - Rede de Informações para o Terceiro Setor <http://www.rits.org.br>, criada em 1997 e atualmente detentora de título de Oscip - Organização da Sociedade Civil de Interesse Público.
} 
rede social na qual se baseia a abordagem proposta implica ações coletivas guiadas por uma racionalidade estratégica, diferenciando-se, assim, das relações interpessoais ou intergrupais que emergem cotidianamente. Ou seja, ainda que mantenham um certo grau de informalidade nas suas interconexões, as redes sociopolíticas são obrigatoriamente regidas por alguma institucionalidade e alguma meta sociohistórica de transformação da realidade presente em torno da qual se articula.

A organização em redes e fóruns quer ajudar a construir dinâmicas sociais, que incorporem e atuem concretamente com a pluralidade organizativa e temática presente na sociedade civil brasileira, considerando os diversos campos e dimensões da luta social e política, e, acima de tudo, compreender que a transformação das relações desiguais e injustas presentes na sociedade se dá em processo de acúmulo de forças, no qual se afirmam vários sujeitos sociais em vista do protagonismo plural. Como forma de expressar o compromisso comum com este conjunto de aspectos, Inter-Redes tem na diversidade dos sujeitos políticos, dos temas, das questões e das perspectivas o ponto de partida da ação. Tem como eixo central a ação articulada e coletiva em vista da promoção de direitos e da proposição de políticas, marcadas pela qualificação da participação cidadã e do fortalecimento dos espaços públicos de interlocução dentro da sociedade, dos setores organizados da sociedade civil com o conjunto da sociedade, destes entre si e com os governos (extraído do site $<$ http://www.inter-redes.org.br>)".

\subsection{Demandas populares}

O primeiro "ensaio" de articulação colaborativa de movimentos sociais como novo protagonismo cidadão, visando a participação popular e o controle social na formulação de políticas públicas, ocorreu durante 0 processo Constituinte, entre 1986 e 1988, que possibilitou a transição das alianças de resistência à ditadura militar para rearranjos de articulações políticoideológicas e político-sociais diferenciadas. Nesse contexto surgem três importantes fóruns nacionais até hoje ativos: o de reforma urbana (FNRU), o de defesa dos direitos da criança e do adolescente (FNDCA) e o de participação popular (FNPP).

O Fórum Nacional de Reforma Urbana nasceu em 1987, para inserir a plataforma da Reforma Urbana na pauta da Assembléia Nacional Constituinte. Mas o próprio fórum reconhece que os avanços têm sido lentos, em função da complexidade e abrangência que envolve a proposta de "mudar a realidade de injustiça e desigualdades nas cidades, em todo o país", através de políticas que garantam direitos básicos de moradia de qualidade, com água e saneamento; transporte acessível e eficiente, que facilite a mobilidade das pessoas para trabalho e lazer; regularização fundiária de favelas e assentamentos informais; direitos humanos como base da política de 
segurança pública. A reforma urbana é também um setor politicamente delicado, pelo jogo de poder que envolve. A construção de moradias populares via recursos para associações e cooperativas habitacionais autogestionárias, como pleiteado pelo FNRU, por exemplo, atinge diretamente os interesses corporativos e clientelistas das grandes empreiteiras e dos políticos que elas apóiam (através de financiamento a campanhas).

Já o Fórum Nacional Permanente de Entidades Não-Governamentais de Defesa dos Direitos da Criança e do Adolescente atua desde 1988 no terreno da institucionalidade jurídica, pela garantia de direitos desse segmento específico da população. Suas táticas bem sucedidas de mobilização pela aprovação do capítulo da criança e do adolescente da Constituição, e pelo Estatuto da Criança e do Adolescente (1990), conferiram-Ihe reconhecimento e legitimidade diante dos atores sociais ligados às questões da infância e da adolescência. O FNDCA está hoje envolvido em praticamente todas as instâncias consultivas e decisórias dessa temática, assumindo responsabilidades de articulação, acompanhamento, monitoramento e denúncias de omissões e transgressões dos direitos. Favorecido pelo redirecionamento da aplicação de recursos para políticas focalizadas (em vez de universalistas, como é o caso da reforma urbana), empenha- se também na "qualificação da sociedade civil" para atuar na área.

A experiência da participação popular na Constituinte foi levada à gestão municipal a partir de 1990, "como um instrumento estratégico para a consolidação e o aprofundamento da democracia, condição indispensável para a elaboração, deliberação e controle social das políticas públicas, assim como para as grandes transformações sociais". É nesse contexto que nasce o Fórum Nacional de Participação Popular (FNPP), cuja trajetória está diretamente ligada à dos Orçamentos Participativos, das conferências setoriais e dos conselhos municipais. Seus principais desafios, hoje, são: a criação de mecanismos de participação e controle social sobre as decisões da política econômica; a proposição de uma "arquitetura da participação" que supere a pulverização e compartimentação dos espaços consultivos e a fragmentação das políticas; a qualificação dos instrumentos de consulta e participação direta, como os plebiscitos, referendos, projetos de lei de iniciativa popular e audiências públicas; e a utilização de novas metodologias, através de diversas linguagens, nas práticas de educação para a cidadania, sobretudo com as populações excluídas desses processos. 


\subsection{Do ecológico ao socioambiental}

O segundo contexto de fomento de inovação organizativa corresponde ao processo de preparação e realização do Fórum Global, evento paralelo e alternativo à Conferência da ONU sobre Meio Ambiente e Desenvolvimento (ECO-92 ou Rio-92), liderado a partir de 1990 pelo Fórum Brasileiro de ONGs e Movimentos Sociais para o Meio Ambiente e o Desenvolvimento (FBOMS). Criado com a incumbência de facilitar a participação da sociedade civil no mega-evento, este Fórum teve como principal desafio criar consensos entre as ONGs tradicionais no campo do desenvolvimento social e os ecologistas neófitos na pauta do desenvolvimento sustentável, visando à produção de documentos e posições coletivos. A empreitada foi facilitada pela comunicação a distância, através da primeira ligação não exclusivamente acadêmica à Internet no Brasil, consolidando o Fórum como um dos principais atores no processo de articulação e consolidação da redes ambientalistas brasileiras e de trânsito internacional.

Atualmente o FBOMS agrega cerca de 550 entidades em todas as regiões do país e possui representantes em mais de 20 instâncias consultivas e/ou decisórias governamentais, como o Conselho Nacional do Meio Ambiente (Conama), a Comissão Nacional de Biodiversidade (Conabio), Comissão Nacional de Florestas (Coba- flor), Conselho Nacional de Recursos Hídricos (CNRH), Comissão Nacional para as Políticas de Desenvolvimento Sustentável e Agenda 21 (CPDS) e o Conselho Nacional de Saúde (CNS). Além disso, participa de eventos internacionais relativos à implantação de compromissos ligados ao desenvolvimento sustentável, em reuniões da Comissão de Desenvolvimento Sustentável da ONU (CDS), em Conferências das Partes (COP) da Convenção da Biodiversidade e da Convenção-Quadro sobre Mudanças Climáticas, e em reuniões da sociedade civil organizada paralelas às reuniões ministeriais da Organização Mundial do Comércio, como em Hong Kong, em 2005. Em março de 2006, o FBOMS organizou o Fórum Global da Sociedade Civil "BemVindo ao Mundo Real", durante a COP-8 da Convenção da Biodiversidade em Curitiba.

O intercâmbio de informações e experiências no processo de preparação e realização do Fórum Global da ECO-92 também propiciou a formação das mais importantes redes ambientalistas do país, que juntas cobrem quase todos os biomas nacionais ${ }^{10} \mathrm{e}$ as áreas-alvo dos maiores projetos de infra-estrutura "modernizadora", de grande impacto socioambiental. Logo após

\footnotetext{
${ }^{10}$ As exceções ficam por conta da ASA - Associação do Semi-Árido, criada mais tarde, em 1999, no contexto do bioma Caatinga; e da novata Rede Bioma Pampa, criada em junho de 2006 (ver mapa do IBGE em <http://mapas.ibge.gov.br/biomas2/viewer.htm>).
} 
a Conferência, ainda em 1992, surge o GTA - Grupo de Trabalho Amazônico, que se organiza em 18 coletivos espalhados pelos nove estados da Amazônia Legal, e cujo número de entidades filiadas já passa de 600 (dados de 2006), entre organizações e movimentos sociais de agricultores, seringueiros, indígenas, quilombolas, quebradeiras de coco babaçu, pescadores, ribeirinhos, além de entidades ambientalistas, de assessoria técnica, de comunicação comunitária e de direitos humanos.

Em seguida, é criado o Formad - Fórum Mato-grossense de Meio Ambiente e Desenvolvimento, cujas 33 entidades filiadas estão hoje empenhadas na "sensibilização e mobilização de jornalistas, educadores do ensino público e sociedade em geral" sobre a importância e os benefícios das áreas protegidas para a sustentabilidade social, econômica, cultural e ambiental da região", alvo dos impactos da expansão da fronteira agrícola e de megaprojetos de infra-estrutura, como a pavimentação da rodovia BR 163, que liga Cuiabá (MT) a Santarém (PA), cortando a Amazônia em um dos trechos de maior diversidade biológica e cultural.

Ainda em 1992, é articulada a Rede Cerrado, que atualmente reúne mais de 80 entidades de trabalhadores rurais, extrativistas, indígenas, quilombolas, geraizeiros, quebradeiras de coco, pescadores e ONGs identificadas com a causa socioambiental do bioma. Para se vincular à rede, todas devem se comprometer a cumprir o Tratado dos Cerrados, documento elaborado durante o Fórum Global, alertando para os prejuízos ambientais e sociais trazidos pelo rápido processo de ocupação agropecuária da região (beneficiado por incentivos governamentais e multilaterais, durante as três últimas décadas).

A idéia de criar a Rede de ONGs da Mata Atlântica (RMA) também nasceu durante o Fórum Global, como forma de intercâmbio e de apresentação de soluções que, individualmente, as entidades locais não seriam capazes. Para facilitar o acompanhamento das políticas da Mata Atlântica e a maior participação nos debates com o Ministério do Meio Ambiente, o Banco Mundial, o Congresso Nacional e outras instâncias decisórias, a RMA transferiu sua sede de São Paulo para Brasília e criou um banco de dados com informações sobre as seguintes áreas de atuação: Acompanhamento legislativo, Agroecologia, Biodiversidade, Capacitação, Comunidades Tradicionais, Consultoria, Cultura, Denúncias, Desenvolvimento sustentável, Direito /assessoria jurídica, Ecoturismo, Educação Ambiental, Fiscalização, Gestão Ambiental, Parques, reservas, RPPNs ${ }^{11}$, Pesquisa, Políticas Públicas, Produção de mudas, Recuperação de Áreas degradadas, Re-

\footnotetext{
${ }^{11}$ RPPN - Reserva Particular do Patrimônio Natural.
} 
cursos Humanos, Saúde, Unidades de Conservação.

O Fórum da Amazônia Oriental (FAOR) foi criado em junho de 1993, durante a I Conferência da Sociedade Civil Organizada sobre Meio Ambiente e Desenvolvimento: Combate à Fome e à Miséria na Amazônia, um duplo desdobramento da ECO-92 e da Ação da Cidadania. Hoje se apresenta como "uma rede mista, plural e horizontal de entidades, concebida como um fórum de articulação para a democratização de políticas públicas e uma plataforma estratégica de discussão sobre direitos humanos, desenvolvimento e sustentabilidade na cidade e no campo da Amazônia". Suas ações são capilarizadas pelo trabalho de uma "Coordenação Ampliada" formada por dez representantes subregionais por estado e nove grupos de trabalho temáticos (ver Quadro 1).

Em 1994, cerca de 100 ONGs e "organizações de base" de Brasil, Argentina, Bolívia, Paraguai e Uruguai formaram a Coalizão Rios Vivos, motivadas pela preocupação com a crescente destruição dos sistemas da bacia do Prata. Essas entidades iniciaram uma campanha contra o mega projeto da Hidrovia Paraná-Paraguai (3.442 quilômetros até o Uruguai) que colocaria em risco várias áreas úmidas, inclusive o Pantanal, e que acabou cancelado em 1998. Hoje a Rios Vivos se apresenta como uma coalizão de mais de 300 organi- zações com diferentes áreas de atuação, entre comunidades indígenas, populações tradicionais, organizações não-governamentais, sindicatos e pesquisadores da América Latina, Estados Unidos e Europa. Suas ações prioritárias de mobilização e intervenção giram em torno de quatro programas: Conservação, restauração e uso sustentável das águas continentais; Agricultura e a expansão da fronteira agrícola com enfoque particular para a monocultura da soja; Energias limpas: perspectivas sociais e ambientais da produção de energia (represas, fósseis, economia e eficiência); Controle social dos bancos multilaterais e os impactos de intervenção no desenvolvimento das regiões.

\subsection{A especialização temática}

A partir de 1994 inicia-se um processo de especialização das ONGs e das suas redes em função de novas demandas de cidadania, de garantia de direitos, de participação nos processos decisórios das políticas públicas e de intensificação dos efeitos sociais e ambientais da globalização econômica. No caso das articulações vinculadas à Inter-redes, observam-se as seguintes tendências:

a) questões de gênero, na qual se enquadram a Articulação de Mulheres Brasileiras (AMB) e a ABGLT - Associação Brasileira de Gays, Lésbicas, Bissexuais, Travestis e Transexuais; 
b) disputa pela utilização dos fundos públicos e mobilização de recursos estatais, com foco no combate à pobreza, às desigualdades e à exclusão social, e na garantia de direitos universais, como educação, saúde e segurança alimentar (tema do FBSAN), para os quais torna-se fundamental o controle social sobre o orçamento público (alvo do FBO);

c) novas abordagens socioambientais: 0 lixo como paradigma da produção e do consumo insustentáveis e da exploração do trabalho infantil (FNLC); a quebra do monopólio de acesso à terra, à água e a outros meios de produção como estratégia de desenvolvimento humano sustentável, pregado pela Articulação do Semi-árido (ASA); os conceitos de "injustiça ambiental" e "racismo ambiental" qualificando a vulnerabilidade de certas populações (RBJA); o conceito de agroecologia como alternativa para a produção e consumo agrícolas, que vinha sendo desenhado por algumas ONGs desde os anos 90 e representa uma união de forças para o enfrentamento do poder do agronegócio (ANA);

d) o enfrentamento contra-hegemônico das grandes questões do capitalismo globalizante, mediante confronto com as organizações financeiras multilaterais (Rede Brasil); aliança continental pela integração dos povos latino-americanos contra os novos blocos de poder regional (Rebrip); e) redes plurais de alternativa de produção e consumo: economia solidária (RBSES) e comércio justo (Faces Brasil).

A Articulação de Mulheres Brasileiras define-se como uma "organização política não partidária que articula e potencializa a luta feminista e a ação política das mulheres no plano nacional e internacional". Em 2002, num contexto pré-eleitoral, com disputas acirradas, a Conferência Nacional da AMB discutiu e aprovou a Plataforma Política Feminista, que se tornou um instrumento dos movimentos de mulheres para o diálogo, crítico e provocativo, para o confronto e para a negociação com outras forças políticas e sociais no Brasil. O documento foi elaborado a partir da mobilização de 5.200 ativistas que participaram dos debates ocorridos em 26 conferências estaduais, realizadas entre março e maio daquele ano. Cerca de 2 mil mulheres participaram da Conferência que aprovou a Plataforma, "uma expressão da diversidade dos movimentos sociais e da capacidade de aliança entre feministas".

A Associação Brasileira de Gays, Lésbicas, Bissexuais, Travestis e Transexuais (ABGLT) - criada em 1995, tornou-se "uma rede nacional" de 203 organizações, sendo 141 grupos de gays, lésbicas, travestis e transexuais, e mais 62 organizações colaboradoras voltadas para os direitos humanos e Aids. Atualmente a ABGLT tem cinco linhas de trabalho prioritárias: a 
campanha Brasil Sem Homofobia; o trabaIho de influência na Resolução Brasileira na ONU sobre Orientação Sexual e Direitos Humanos; advocacy ${ }^{12}$ para aprovação de leis e garantia de orçamento para políticas afirmativas voltadas para GLBTs; garantia da manutenção de recursos para prevenção e assistência em HIV/Aids para homens que fazem sexo com homens; e promoção do Estado Laico.

O Fórum Brasileiro de Segurança Alimentar e Nutricional (FBSAN), criado em 1998, é hoje uma articulação de entidades, movimentos sociais, indivíduos e instituições que tem entre os seus objetivos e ações: fomentar a elaboração de propostas de políticas e ações públicas nacionais e internacionais em Segurança Alimentar e Nutricional e Direito Humano à Alimentação; inserir esta temática nas agendas políticas nacional, estadual e municipal, e colaborar para o debate internacional sobre o tema; estimular o desenvolvimento de a-

\footnotetext{
12 "Advocacy significa lutar por uma causa, por meio de conscientização da sociedade, capacitação de agentes transformadores, mobilização da população e acompanhamento da atuação do poder público", segundo a Ágere - Cooperação em Advocacy, "uma ONG especializada em treinar outras ONGs para fazer advocacy ou apoiá-las em suas ações junto ao executivo e Legislativo Federal em Brasília" <http://www.agere.org.br>. Para Rodrigues (1999), o termo "aponta para uma ação coletiva, política, pública e embasada em valores e racionalidades", diferenciando-se do lobby, que se refere "a um tipo de ação política em favor de grupos ou corporações específicas", na qual "estão em pauta interesses privados, geralmente de ordem financeira". Advocacy envolve "Promoção de Direitos, quando se visa ampliar o espectro de direitos já conquistados" ou "Defesa de Direitos, quando há risco de violação dos mesmos", segundo Azevedo (2003).
}

ções locais/municipais de promoção da segurança alimentar e nutricional; colaborar para a capacitação dos atores da sociedade civil para participação efetiva nos diferentes espaços de gestão social; denunciar e monitorar as respostas governamentais sobre violações ao direito à alimentação. Paralelamente à consolidação do Fórum Nacional, vêm sendo criados fóruns e conselhos de segurança alimentar (Conseas) estaduais a partir de mobilizações da sociedade organizada em torno do tema.

As 55 entidades que compõem o Fórum Brasil do Orçamento (FBO), criado em 2002, lutam para direcionar mais recursos federais às políticas sociais; para ampliar o conhecimento da população sobre os gastos públicos; e, assim, "aumentar a participação social no acompanhamento e na pressão por uma execução orçamentária transparente e de fácil entendimento". Essas entidades consideram que o orçamento não é apenas uma peça técnica necessária para o controle social dos gastos públicos, mas principalmente um instrumento de planejamento e devolução para a sociedade de parte da riqueza produzida pelo trabalho, na forma de financiamento às políticas promotoras da justiça social. Atualmente o Fórum promove uma campanha pela construção democrática de uma Lei de Responsabilidade Fiscal e Social, e defende a ampla participação na definição e 
controle do orçamento público, sobretudo das camadas sociais historicamente marginalizadas do processo decisório de políticas públicas no Brasil.

O Fórum Nacional Lixo \& Cidadania (FNLC), criado em 1998, é um exemplo de abordagem de política pública ao mesmo tempo universalista e focalizada. A proposta de implantação do Programa Nacional Lixo \& Cidadania, com a qual se comprometeram mais de 56 entidades (incluindo órgãos governamentais, ONGs, entidades técnicas e religiosas), tem como objetivos: a erradicação do trabalho infanto-juvenil nos lixões, propiciando a inclusão social das crianças, com cidadania; a geração de renda para as famílias de catadores, prioritariamente na coleta seletiva; e a "mudança radical da destinação final de lixo, acabando definitivamente com os lixões no Brasil". O Fórum estimula a implantação de fóruns estaduais e municipais; identifica, apóia e divulga experiências bem sucedidas; realiza pesquisa e levantamento de dados sobre os serviços de limpeza urbana no Brasil, abordando os aspectos sociais; faz campanha pelo bolsa-escola para as crianças que vivem no lixo; e articula-se com agentes financiadores "para aplicação dos recursos com uma visão integrada das ações", entre outras iniciativas.

A Articulação do Semi-árido (ASA), lançada em 1999, durante a terceira sessão da Conferência das Partes das Nações
Unidas da Convenção de Combate à Desertificação (COP3), em Recife, tem como base da sua constituição a Declaração do Semi-Árido, documento que sintetiza as percepções sobre a região da caatinga de cerca de 700 entidades, entre ONGs, associações, sindicatos e federações de trabalhadores rurais e urbanos, associações comunitárias, movimentos sociais e organismos de cooperação internacional públicos e privados, além de igrejas católica e evangélica. A ASA fundamenta suas ações "no compromisso com as necessidades, potencialidades e interesses das populações locais, em especial os agricultores e agricultoras familiares", e busca contribuir para a formulação de políticas estruturadoras para o desenvolvimento do semi-árido. A conservação, o uso sustentável e a recomposição ambiental dos recursos naturais do semi-árido, bem como a quebra do monopólio de acesso à terra, à água e a outros meios de produção são os "pilares da estratégia de desenvolvimento humano sustentável" da rede.

A Rede Brasileira de Justiça Ambiental (RBJA) talvez seja a única das redes sociopolíticas brasileiras que tenha nascido em um campus universitário: foi durante o Colóquio Internacional sobre Justiça Ambiental, Trabalho e Cidadania realizado na Universidade Federal Fluminense, em 2001, que reuniu ativistas de movimentos sociais, sindicatos de trabalhadores, 
ONGs, entidades ambientalistas, organizações de afrodescendentes e indígenas, e pesquisadores universitários. A Rede baseia-se em um "conceito aglutinador e mobilizador, por integrar as dimensões ambiental, social e ética da sustentabilidade e do desenvolvimento, freqüentemente dissociados nos discursos e nas práticas". A iniciativa agrega um conjunto de práticas já existentes no país que podem ser identificadas como de Justiça Ambiental, embora não utilizassem a expressão. Este conceito "denuncia, entre outras coisas, a lógica que define os locais onde serão instalados os grandes empreendimentos de mineração, as barragens das hidrelétricas, a passagem de linhas de transmissão de eletricidade, de oleodutos e outras obras, como depósito de lixos tóxico ou de resíduos químicos, que se concentram, de modo predominante, em locais onde vivem populações pobres." A Rede se propõe a realizar "um trabalho de pesquisa, divulgação e pressão política no sentido de inserir na agenda pública uma perspectiva de preservação ambiental que comece a ser pensada também em termos de distribuição e justiça".

Agroecologia é outro conceito que ganhou força entre movimentos sociais, comunidades rurais e ONGs antes de ser incorporada como pauta governamental e até mesmo na pesquisa acadêmica. Mas foi só no I Encontro Nacional de Agroeco- logia (ENA), realizado em 2002, que pela primeira vez foi exibida, em escala nacional, "a riqueza e diversidade das experiências em agroecologia existentes no país". A ampla participação no encontro, com reuniões regionais, estaduais e microregionais prévias, serviu de base para a criação da ANA - Articulação Nacional de Agroecologia, que tem entre os seus propósitos "o combate ao modelo de desenvolvimento ambientalmente predatório e socialmente excludente que tem predominado no Brasil nos últimos 50 anos, baseado na chamada 'Revolução Verde', e que no momento atual vem se expressando politicamente no 'agronegócio'”.

A Rede Brasil sobre Instituições Financeiras Multilaterais foi constituída em 1995, após dois anos de debate e avaliação crítica sobre a atuação das instituições financeiras multilaterais (IFMs), como Banco Mundial, o Banco Interamericano de Desenvolvimento (BID) e o Fundo Monetário Internacional (FMI), no Brasil. A rede foi criada com base na percepção de que políticas e projetos financiados por essas instituições no país deveriam ser tratados como uma questão de interesse nacional, com ênfase nas responsabilidades das várias partes direta e indiretamente envolvidas. As organizações e movimentos participantes desse processo de discussão avaliaram que ações conjuntas ou articuladas da sociedade civil junto às IFMs e ao go- 
verno brasileiro poderiam apresentar resultados mais amplos e eficazes para o enfrentamento e a superação dos problemas identificados do que iniciativas individuais, fragmentadas e dispersas, como vinha ocorrendo até aquele período. Atuando de forma colaborativa, os participantes da rede realizam discussões coletivas sistemáticas, disseminam informações qualificadas, produzem consensos sobre as questões que identificam, subsidiam ações e intervenções frente ao governo e às IFMs, e abrem canais de interlocução com essas instâncias de poder sobre políticas e projetos de desenvolvimento.

A oposição à liberalização comercial e financeira predominante nos acordos econômicos atualmente em curso na América Latina motivou a formação da Rebrip Rede Brasileira pela Integração dos Povos, em 2001. Através desta articulação, ONGs, movimentos sociais, entidades sindicais e "associações profissionais autônomas e pluralistas" buscam alternativas para a integração hemisférica opostas à lógica dos tratados de desregulamentação financeira e comercial, nos quais incluem-se a Organização Mundial do Comércio (OMC), a Área de Livre Comércio das Américas (ALCA) e outros acordos comerciais bilaterais e entre regiões, como 0 acordo Mercosul- União Européia. Os integrantes da rede subsidiam iniciativas sociais com informações, análises e propostas a partir de seus acúmulos de conhecimentos setoriais e temáticos (ver Quadro 1). A Rebrip contribui também para os esforços da Aliança Social Continental, que reúne organizações sociais e sindicais das Américas em um amplo movimento de resistência aos tratados de livre comércio envolvendo países da região.

Relações socioeconômicas solidárias são o foco de duas outras redes brasileiras, que têm na composição pluralista de "interessados" nas ações da rede (stakeholders ${ }^{13}$ ) uma outra característica em comum, que as aproxima do perfil de "movimentos em rede". O Fórum de Articulação do Comércio Ético e Solidário do Brasil, ou simplesmente FACES do Brasil, constituiuse em 2002 com o objetivo de "fomentar a criação de um ambiente favorável à construção e implementação de um sistema brasileiro de comércio ético e solidário, promovendo a equidade e a inclusão social". Para este fórum, comércio ético e solidário (ou comércio justo, no contexto internacional) é baseado em relações éticas, transparentes e co-responsáveis entre os diversos atores da cadeia produtiva, e também uma forma de empoderamento dos trabalhadores assalariados, produtores e agricultores familiares, que estão em desvantagem ou marginalizados pelo sis-

\footnotetext{
${ }^{13}$ Termo de difícil tradução, muito utilizado por organizações internacionais, que neste contexto refere-se às pessoas que atuam na rede de forma "interessada" porque podem ser beneficiadas pelos seus resultados.
} 
tema convencional de comércio. Em 2004, o fórum iniciou um mapeamento de grupos produtivos brasileiros com potencial para participar do comércio ético e solidário, que ainda não estava concluído à época deste artigo.

Com um noção mais ampla desse campo emergente de relações socioeconômicas, a Rede Brasileira de Socioeconomia Solidária (RBSES) vem atuando desde 2000 com um claro projeto de confrontar o sistema e a globalização capitalistas, a partir "da base", isto é, das redes de economia solidária que integram empreendimentos e organizações locais, "que podem conformar fóruns e redes estaduais e estabelecer comissões em diversos âmbitos, inclusive de caráter regional e nacional". Com seu método, a RBSES afirma "os valores do trabalho emancipado, propriedade e gestão cooperativas dos meios de produzir as riquezas e reproduzir a vida, a constituição de sujeitos do seu próprio desenvolvimento pessoal e social e o combate a toda forma de opressão e exploração econômica, política e cultural". A relação com o Estado "varia conforme o caráter dos poderes constituídos, podendo ser de parcerias, acordos pontuais e ações de pressão ou resistência, preocupando-se com a legislação cooperativa, linhas de crédito oficiais a juros condizentes com empreendimentos sociais, acesso, em tempo hábil, a editais de licitação para for- necimento de bens e serviços ao Estado, e políticas públicas de fomento aos empreendimentos sociais".

\section{IDENTIDADE, LEGITIMIDADE E PRO- CESSOS DE ENREDAMENTO}

Ao contrário das redes sociais interpessoais, tradicionalmente informais e espontâneas, as redes de ONGs e movimentos sociais brasileiras vêm se formalizando cada vez mais por meio de algum tipo de "contrato social" entre as entidades participantes (carta de princípios, termo de adesão, acordo de convivência, regimento interno, tratado, estatuto, convenção, etc), e de mecanismos operacionais ou de "gestão" (coordenação geral/ nacional, comitê facilitador, conselho deliberativo, secretaria-executiva, instâncias regionais, estaduais, subregionais, etc). O objetivo principal desses "contratos" é gerar um comprometimento dos participantes com o "ideário" da rede, no qual se baseia a sua legitimidade junto à sociedade em geral, aos "parceiros" (apoiadores e mantenedores), aos aliados táticos, a certas estruturas de poder (decisores das políticas públicas, atores que exercem influência sobre a mobilização de recursos do Estado, entre outros), e às partes interessadas em suas ações (stakeholders), aí incluídos os beneficiários diretos e indiretos.

Os termos de compromisso referemse ao "conjunto de crenças, valores, ideo- 
logias, formas de conceber e de fazer as ações sociais coletivas concretas", que os participantes compartilham e ao qual associam suas identidades individuais (ou institucionais), como projeto, em um horizonte de longa duração (GOHN, 2005, p. 35-36). Já os mecanismos operacionais visam garantir a dinâmica e a "eficácia" da rede e são sintomas do grau de descentralização e horizontalidade alcançados (ou propostos), da mesma forma que os processos decisórios adotados, se por consenso ou "centralismo democrático" (votação), independente do tipo de instância em que as decisões são tomadas (assembléia geral, ordinária, extraordinária; oficina de planejamento; encontros anuais/ bienais, etc). Ou seja, a formalização dessas redes não visa simplesmente atribuir-Ihes legalidade institucional e criar normas de funcionamento, mas representam "um modo processual construtivo", baseado em agenciamentos de subjetivação e de "enunciação que lhes dê um suporte expressivo", no sentido de Guattari (1990, p.28).

Outro sintoma da horizontalidade da rede é a sua territorialidade, que expressa a capilaridade da sua articulação e sua inserção social, e não necessariamente a abrangência espacial. A capilaridade da $\mathrm{AMB}$, por exemplo, é constituída por fóruns, núcleos, redes e articulações formados em cada um dos 27 estados brasileiros e descrita como uma forma de "institucio- nalidade não burocrática marcada pelos acordos políticos entre os setores do movimento representados". Já o Fórum $\mathrm{Na}$ cional de Reforma Urbana ainda precisa fomentar e fortalecer os fóruns regionais do Norte, Nordeste e Centro Oeste para que possa garantir a "nacionalidade" das suas pautas. Outras redes constroem a sua territorialidade em torno de espacialidades geopolíticas, como o GTA, na Amazônia Legal, e o FAOR, na Amazônia Oriental; ou de referenciais socioambientais, como a ASA, a Rede Cerrado e a Rios Vivos, que atuam no contexto de biomas e ecossistemas.

Os grupos de trabalho (GTs) temáticos, que funcionam como uma espécie de "divisão do trabalho" coletivo, exercem um importante papel na capacidade de articulação da rede e na produção, apropriação e compartilhamento de conhecimento e saberes especializados, que orientam escolhas ideológicas, estratégias discursivas de contra-argumentação e táticas de participação e intervenção nas arenas e agendas da esfera pública. Na Rede da Mata Atlântica, por exemplo, os GTs funcionam por meio de listas de discussão eletrônicas e da realização de oficinas de trabalho, e são considerados "espaços onde são discutidas e formuladas análises e propostas de intervenção das entidades a fim de colocar em prática o Plano Estratégico" da Rede. Na Associação Nacional de Agroe- 
cologia, os grupos são constituídos por representantes de organizações e de movimentos sociais inseridos nas diferentes redes regionais e com experiências significativas nas temáticas trabalhadas (ver Quadro 1).

\begin{tabular}{|c|c|}
\hline \begin{tabular}{|l}
$\begin{array}{l}\text { Rede } \\
\text { (sigla) }\end{array}$ \\
\end{tabular} & Temas dos grupos \\
\hline ANA & $\begin{array}{l}\text { - Acesso aos mercados } \\
\text { - Biodiversidade } \\
\text { - Construção do conhecimento } \\
\text { agroecológico } \\
\text { - Financiamento } \\
\text { - Gênero } \\
\text { - Informação }\end{array}$ \\
\hline FAOR & $\begin{array}{l}\text { - Agenda local } \\
\text { - Água e energia } \\
\text { - Crédito e financiamento } \\
\text { - Desenvolvimento urbano } \\
\text { - Economia solidária } \\
\text { - Educação e protagonismo juvenil } \\
\text { - Gênero e preconceitos } \\
\text { - Indígenas e povos tradicionais } \\
\text { - Terra, meio ambiente e } \\
\text { desenvolvimento }\end{array}$ \\
\hline FBOMS & $\begin{array}{l}\text { - Agenda } 21 \\
\text { - Água } \\
\text { - Clima } \\
\text { - Comércio e meio ambiente } \\
\text { - Direito ambiental } \\
\text { - Educação ambiental } \\
\text { - Energia } \\
\text { - Florestas } \\
\text { - Integração } \\
\text { - Juventude } \\
\text { - Químicos } \\
\text { - Sociobiodiversidade } \\
\text { - Turismo sustentável }\end{array}$ \\
\hline REBRIP & $\begin{array}{l}\text { - Agricultura } \\
\text { - Comércio e meio ambiente } \\
\text { - Gênero } \\
\text { - Parlamento } \\
\text { - Propriedade intelectual } \\
\text { - Serviços }\end{array}$ \\
\hline RMA & $\begin{array}{l}\text { - Área de preservação permanente } \\
\text { e reserva legal } \\
\text { - Atividades sustentáveis } \\
\text { consumo consciente } \\
\text { - Unidades de conservação }\end{array}$ \\
\hline
\end{tabular}

Quadro 1: Temáticas trabalhadas
"Eles são os principais canais de articulação da ANA, fazendo a ponte entre as experiências locais e regionais e o debate sobre as políticas públicas, aprofundando análises e propostas sobre temas emergentes no campo de desenvolvimento rural brasileiro e influenciando no debate público em torno desses temas".

Também fazem parte desses mecanismos a disseminação de informação e as ações comunicativas para mobilização de ativistas, influência na opinião pública e pressão sobre os decisores de políticas públicas e estratégias mercadológicas. $\mathrm{Na}$ RMA, cada grupo tem a incumbência de articular ações de monitoramento e mobilização, formular propostas e realizar campanhas no seu domínio temático. Nesses processos, tem sido fundamental o trabaIho colaborativo entre diversas entidades da sociedade civil, incluindo movimentos reivindicativos locais e de grupos, sindicatos e comissões temáticas de partidos para criar interlocuções qualificadas com as instâncias de poder (parlamentares, governos, empresariado e organizações multilaterais). Os exemplos a seguir mostram a variedade de temas com que lidam essas redes, que supõe pessoal qualificado tanto nos conteúdos (conhecimento especializado) quanto no gerenciamento e disseminação das informações acumuladas.

A aprendizagem nos GTs tem gerado uma competência técnica e operacional 
transmitida tanto oralmente - em inúmeros encontros, seminários e atividades de capacitação - quanto através de documentos de livre circulação ou da troca de idéias e experiências em listas e grupos de discussão. Um "efeito colateral" dessa competência acumulada foram as perdas importantes que alguns movimentos, organizações e redes sofreram em seus quadros no Governo Lula (sobretudo no primeiro mandato), em função do que Gohn (2005, p. 39) identifica como a "passagem de atores sociais do espaço público, na sociedade civil, para atores políticos, para atuarem institucionalmente junto às políticas públicas". Ou seja, ativistas e assessores dos movimentos, detentores de conhecimento especializado e experiência política acumulada em negociações com as instâncias de poder exercem agora o papel de antagonistas ou de "aliados" dentro da base "inimiga", dependendo da complexidade do jogo de interesses da questão em disputa.

\section{DESAFIOS À ANALISE DE REDES SOCIOPOLÍTICAS}

No jargão das ONGs, o termo "rede" refere-se a pessoas de uma organização que se comunicam com pessoas de outra organização ou movimento, por qualquer meio, para articular uma ação. "Redes de ONGs" são, portanto, um modo de articulação estratégica.
[...] elas são descritas como "processos dinâmicos permanentes que estabelecem laços múltiplos, descontínuos e redundantes entre pessoas e entre grupos, formais e informais [...]. O essencial nestas redes não é a estrutura, mas os processos descentralizados de comunicação e de tomada de decisões. Apóiam-se em sólidos relacionamentos interpessoais que resistem ao teste do tempo (PEÓN, 1993, apud FERNANDES, 1994, p.130, apud LOPES, p.189).

Villasante (1999) defende que os estudos das redes sociais contemporâneas não devem seguir um percurso rigidamente pré-determinado, preocupado com um modelo a construir, mas devem se ater mais detalhadamente ao que chama de "sintomas" das experiências concretas de enredamento. Foi o que se buscou fazer neste ensaio analítico, que acaba por revelar mais lacunas e desafios a perseguir, do que orientações metodológicas a seguir, embora algumas tendências possam ser indicadas.

A observação do perfil dos participantes da Inter-redes permitiu identificar três "padrões" de articulações: as redes interorganizacionais, nas quais todos os participantes atuam apenas institucionalmente, por delegação ou representação do projeto político da entidade à qual estão profissionalmente vinculados; e as redes sociais plurais, que se diferenciam pelos interesses das suas ações: as formadas por indivíduos e atores sociais diversos (ativistas de movimentos, líderes comunitá- 
rios, pesquisadores, advogados, representantes de ONGs, de governos, de empresas, etc) que cooperam para a promoção ou defesa dos direitos de outrem (advocacy); e as formadas majoritariamente por indivíduos e atores que são "partes interessadas" (stakehorders) ou beneficiadas nos processos do quais participam colaborativamente (como produtores, comerciantes e consumidores empenhados no desenvolvimento de uma economia solidária ou de comércio justo e das práticas agroecológicas).

O desafio dessas configurações para a análise de redes sociais está na distinção entre o indivíduo, o sujeito e o ator, já que uma pessoa pode participar de diferentes redes representando a mesma organização ou ocupando papéis e funções diferentes em cada uma delas; ou a mesma organização pode participar de várias redes simultaneamente, representada por pessoas diferentes. Ao contrário das redes sociais de indivíduos, geralmente construídas a partir de relações cotidianas, as redes de ONGs e movimentos sociais são formas organizativas fomentadas por pessoas que articulam entidades da sociedade civil em torno de idéias, interesses, necessidades e/ou objetivos (estratégicos e táticos) comuns. A condição em que cada indivíduo participa de uma articulação (representando um projeto institucional, agindo com autonomia no interesse de outrem ou em seu próprio interesse) certamente influi qualitativamente na dinâmica da rede.

No caso da "representação coletiva", a escolha obedece a uma racionalidade relativa ao conhecimento e à experiência de cada indivíduo em relação aos temas em pauta e às arenas políticas na qual se dão os enfrentamentos das instâncias de poder. Há, certamente, diferenças importantes de especificidades de interlocução, de lógica argumentativa, de complexidade sociohistórica e de interesses em jogo entre as arenas em que se debate, por exemplo, a garantia dos direitos de crianças e adolescentes com base em um Estatuto jurídico estabelecido e legitimado; e na que se tenta sobrepor os impactos socioambientais e micro-econômicos da transposição do Rio São Francisco a uma rede de poder clientelista tradicionalmente aprisionadora do Estado; ou ainda quando uma aliança continental de organizações e movimentos populares parte para o enfrentamento dos grandes interesses geopolíticos e corporativos transnacionais na América Latina. A competência individual exigida de cada participante das redes envolvidas nessas disputas é bastante diferenciada e não pode ser ignorada na sua análise.

Toda rede possui uma temática geral, que serve de motivação e aglutinação de seus participantes, e que se desdobra em subtemas gerados por interesses específicos que vão surgindo ao longo do seu de- 
senvolvimento. Mas esse desenvolvimento pode não ser simplesmente contínuo ou descontínuo, rápido ou lento, admitindo posições intermediárias de aceleração e desaceleração, em função de determinadas circunstâncias que animam, fragmentam ou estancam a mobilização. Os graus de participação dependem: do interesse dos integrantes na temática da rede e nos conteúdos nela veiculados; dos estímulos à participação (animação da rede); das ações comunicativas que propiciam a interação dos nós. No caso das redes sociopolíticas, a capacidade de construção de consensos e as estratégias discursivas nos processos de mobilização e interação são também sintomas importantes para a dinâmica de desenvolvimento da rede.

Para verificar a densidade e a dinâmica de enredamento das ONGs e movimentos sociais brasileiros em torno de determinadas questões sociopolíticas seria necessário inventariar todas as afiliações das redes com temáticas afins e mapear seus vínculos entrecruzados. Uma observação informal a esse respeito indica que algumas entidades têm atuação inter-redes mais intensa do que outras em certas áreas de interesse para o seu projeto políti$\mathrm{co}$, não obrigatoriamente centradas em um tema. Nesse tipo de análise importaria observar: os papéis exercidos pelos participantes nas interações e no fluxo de informações; a qualidade dos vínculos estabe- lecidos entre os participantes, os graus de participação, a democratização dos processos decisórios e os conteúdos mobilizadores que circulam pela rede.

Toda rede possui uma face visível, observável a partir da ação e dos relatos de seus participantes, e uma face invisível, resultante do potencial multiplicador de cada nó para fora do seu "ambiente". Nas redes sociopolíticas, a extensão das "teias invisíveis" está diretamente relacionada à sua capilaridade, à sua capacidade de mobilização social e à eficácia de um projeto emancipador.

Portanto, cada rede pode ser investigada de maneiras e ângulos diferentes. Estudos sincrônicos identificam a estrutura da rede, os grupos, as sub-redes, os fluxos de informação, os tipos e qualidades de vínculos entre os participantes, etc.; análises diacrônicas observam e interpretam a evolução da rede, os processos históricos nela contidos, as mudanças e transformações operadas, as memórias acumuladas. O risco dos estudos exclusivamente sincrônicos é o de cair no que Villasante chama de "estudos estereotipados das redes sociais". Já nos estudos diacrônicos é possível observar as "ondas longas" que formam a memória histórica e o legado dos movimentos: "São elementos de socialização e educação política, de hegemonia ou contra-hegemonia, com grande peso histórico tanto a favor como contra a emancipa- 
ção social" (Villasante, 2002, p.33, apud AGUIAR, 2002).

\section{BIBLIOGRAFIA}

AGUIAR, Sonia. Produção compartilhada e socialização do conhecimento em rede: uma abordagem exploratória. Comunicação apresentada no II Seminário Nacional do Programa de Pós-Graduação em Educação da Universidade Federal Fluminense. Niterói: UFF, 2002. Disponível em: < http://www.rits.org.br/redes teste/rd tmes mar2006.cfm>. Acesso em 31 jul. 2007.

AZEVEDO, Maria Amélia. Advocacy em rede. São Paulo: LACRI/IPUSP, 2003 (relatório de trabalho). Disponível em: < http://www.ip.usp.br/laboratorios/lacri/advoc acy.doc>. Acesso em 22 ago. 2007.

CASTELLS, Manuel. O poder da identidade. Rio de Janeiro: Paz e Terra, 2002. 3.ed. 530p. (A era da informação: economia, sociedade e cultura; v.2).

DABAS, Elina Nora. Red de redes: las prácticas de la intervención en redes sociales. Buenos Aires: Paidos, 2003. 176p.

DIANI, Mario; MCADAM, Doug (Eds.). Social movements and networks: relational approaches to collective action. New York, Oxford University Press, 2003. 348p. (Comparative Politics).

GOHN, Maria da Gloria (Org.). Movimentos sociais no início do século XXI: antigos e novos atores sociais. Petrópolis: Vozes, 2003. 144p.

O protagonismo da sociedade civil: movimentos sociais, ONGs e redes solidárias. São Paulo: Cortez, 2005. 120p. (Questões da Nossa Época, 123).

GUATTARI, Félix. As três ecologias. 2.ed. Campinas: Papirus, 1990. 56 p.
INSTITUTO BRASILEIRO DE ANÁLISES SOCIAIS E ECONÔMICAS. Sementes de solidariedade: Betinho e o Ibase na Ação da Cidadania - 1993/97. Rio de Janeiro: lbase, 1998. CD-ROM.

LISBOA, Armando de Melo. Terceiro setor. In: CATTANI, Antonio David (Org.). A outra economia. Porto Alegre, Veraz Editores, 2003.

LOPES, Sonia Aguiar. A teia invisível: informação e contra-informação nas redes de ONGs e movimentos sociais. 1996. 2v. 281fls. Tese (Doutorado em Comunicação/ Ciência da Informação). Escola de Comunicação, Universidade Federal do Rio de Janeiro/lbict, Rio de Janeiro, 1996.

MELUCCI, Alberto. A invenção do presente: movimentos sociais nas sociedades complexas. Petrópolis: Vozes, 2001. 200p.

MONTAÑO, Carlos. Terceiro setor e questão social: crítica ao padrão emergente de intervenção social. São Paulo, Cortez, 2002. 288p.

PARAMIO, Ludolfo. Decisión racional y acción colectiva. Leviatán, Madrid, n.79, p.65-83, 2000. Disponível em: < http://www.iesam.csic.es/doctrab1/decision. pdf>. Acesso em 30 jul. 2007.

RODRIGUES, Almira. Advocacy: uma ação política de novo tipo. Brasília: Cefemea, 1999. Disponível em: < http://www.cfemea.org.br/publicacoes/artig os detalhes. asp? IDArtigo $=6>$. Acessado em: 22 ago. 2007.

SOCZEK, Daniel. ONGs e democracia: metaformoses de um paradigma em construção. Curitiba: Juruá, 2007. 256p.

SUED, Gabriela. Tecnologías de control y tecnologías de libertad: aportes para pensar la construcción de una nueva esfera pública en la era de Internet. Revista de Economía Política de las Tecnologías de la Información y Comunicación, v.6, n.1, eneabr. 2004. 
$<$ http://www.eptic.com.br/gabi.pdf>. Acesso em: 20 ago. 2007.

VILLASANTE, Tomás R. Cuatro redes para hacer transformaciones sustentables. Política y Sociedad, Madrid, n.31, p.37-54, 1999. Disponível em: < http://www.ucm.es/BUCM/revistas/cps/113 08001/ articulos/POSO9999230037A.PDF> Acesso em 01 jun. 2007.

.; GUTIÉRREZ, Pedro M. Redes y conjuntos de acción: para aplicaciones estratégicas en los tiempos de la complejidad social. REDES - Revista hispana para el análisis de redes sociales, Barcelona, v.11, n.2, dic. 2006. Disponível em: $<$ http://revista-redes.rediris.es/pdfvol11/Vol11 2.pdf>. Acesso em 01 jun. 2007.

*Redes e Fóruns vinculados à Inter-Redes citados neste artigo

ABGLT - Associação Brasileira de Gays, Lésbicas e Travestis (1995) <http://www.abglt.org.br/>

AMB - Articulação de Mulheres Brasileiras (1994) -

<http://www.articulacaodemulheres.org.br/> ANA - Articulação Nacional de Agroecologia (2002) -

$<$ http://www.encontroagroecologia.org.br/a na>

ASA - Articulação do semi-árido (1999) $<$ http://www.asabrasil.org.br/>

CRV - Coalizão Rios Vivos (1994) <http://www.riosvivos.org.br/>

FAOR - Fórum da Amazônia Oriental (1993) - <http://www.faor.org.br/>

FACES - Fórum de Articulação do Comércio Ético e Solidário no Brasil (2002) $<$ http://facesdobrasil.org.br/> FBO - Fórum Brasil do Orçamento (2002) $<$ http://www.forumfbo.org.br/>

FBOMS - Fórum Brasileiro de ONGs e Movimentos Sociais para o Meio Ambiente e o Desenvolvimento (1990) -

<http://www.fboms.org.br/>
FBSAN - Fórum Brasileiro de Segurança Alimentar e Nutricional (1998) $<$ http://www.fbsan.org.br/>

FDCA - Fórum de Direitos da Criança e Adolescente (1988) -

$<$ http://www.forumdca.org.br/>

FNLC - Fórum Nacional Lixo e Cidadania (1998) -

<http://www.lixoecidadania.org.br/>

FNPP - Fórum Nacional de Participação Popular (1990) -

<http://www.participacaopopular.org.br/> FNRU - Fórum Nacional de Reforma Urbana (1987) -

$<$ http://www.forumreformaurbana.org.br>

FORMAD - Fórum Mato-Grossense e Meio

Ambiente e Desenvolvimento (1992) -

$<$ http://www.formad.org.br/>

GTA - Grupo de Trabalho Amazônico

(1992) - <http://www.gta.org.br/>

Rede Brasil - Rede Brasil sobre Instituições Financeiras Multilaterais (1995) <http://www.rbrasil.org.br/>

RBJA - Rede Brasileira de Justiça Ambiental (2001) -

$<$ http://www.justicaambiental.org.br/>

RBSES - Rede Brasileira de Socioeconomia Solidária (2000) -

$<$ http://www.redesolidaria.com.br/> (provisoriamente disponível em:

$<$ http://www.ifil.org/redesolidaria/>)

Rede Cerrado (1992) -

<http://www.redecerrado.org.br/>

Rebrip - Rede Brasileira pela Integração dos Povos (2001) $<$ http://www.rebrip.org.br/>

RMA - Rede de ONGs da Mata Atlântica (1992) - <http://www.rma.org.br/>

obs: data de fundação entre parêntesis

Sonia Aguiar

Doutora em Comunicação/Ciência da Informação pelo lbict/UFRJ, com tese sobre redes de ONGs e movimentos sociais, professora aposentada da UFF e pesquisadora-associada do Nupef-Rits Núcleo de Pesquisas, Estudos e Formação da Rede de Informações para o Tereiro Setor $<$ http://www.nupef.org.br> soniaguiar@terra.com.br 


\section{Title}

Organizations and networking for sociopolitical actions

\section{Abstract}

The ways NGOs and social movements have been organizing their collective action and networking in Brazil, mainly over the last 15 years, appear under different denominations: alliance, coalition, coordination, forum, network. These organizational configurations are differentiated from individuals social networks because its nodes must be considered as "collective representations" of interests, necessities and identities of groups, communities and populations. Its collective action involves participative and collaborative processes strongly supported by specialized knowledge production, appropriation and sharing, which guide ideological choices, counter-argumentation discursive strategies, and tactics of intervention in the public sphere arenas and agendas. For this, they need activists and collaborators with both academic expertise and know-how in social fights from local to global ones.

\section{Keywords}

social networks; NGOs and social movements; specialized knowledge; counter-argumentation; strategic racionality.

\section{Título}

Formas de organización y de enredamiento para acciones sociopolíticas

\section{Resumen}

Las formas organizativas basadas en la dinámica del enredamiento entre ONGs y los movimientos sociales han aparecido y fortificado en Brasil, sobretodo en los últimos 15 años, bajo diversas denominaciones: alianza, articulación, coalición, foro, red. Estas configuraciones son distintas de las redes sociales de indi- viduos porque sus nodos son representaciones colectivas" de intereses, de necesidades y de identidades de grupos, de comunidades y de poblaciones. Su acción colectiva implica procesos participativos y colaborativos fuertemente apoyados en la producción, en la apropiación y en el compartir de conocimiento y saber especializado. Estos dirigen las opciones ideológicas, las estrategias discursivas de contraargumentación y las tácticas de intervención de las organizaciones sociales en las arenas y agendas de la esfera pública. Para esto, las redes necesitan contar en sus equipos o entre sus colaboradores con activistas formados en la universidad, pero que también tengan experiencia en las luchas sociales - las locales y las globales.

\section{Palabras Clave}

redes sociales; ONGs y movimientos sociales; saberes especializados; contraargumentación ; racionalidad estratégica. 